\title{
MAKING (SHELF) SPACE FOR VHS: AGFA AND THE PRESERVATION OF GENRE FILM ACCESS COPIES
}

by

Adam Abouaccar

Bachelor of Fine Arts, Concordia University, Montreal, Quebec, 2015

\author{
A thesis \\ Presented to Ryerson University in \\ partial fulfillment of the requirements \\ for the degree of Master of Arts \\ in the program of
}

Film \& Photography Preservation and Collections Management

Toronto, Ontario, Canada, 2019

(C) Adam Abouaccar 2019 


\section{AUTHOR'S DECLARATION FOR ELECTRONIC SUBMISSION}

I hereby declare that I am the sole author of this thesis. This is a true copy of the thesis, including any required final revisions, as accepted by my examiners.

I authorize Ryerson University to lend this thesis to other institutions or individuals for the purpose of scholarly research.

I further authorize Ryerson University to reproduce this thesis by photocopying or by other means, in total or in part, at the request of other institutions or individuals for the purpose of scholarly research.

I understand that my thesis may be electronically available to the public. 


\begin{abstract}
Making (Shelf) Space For VHS: AGFA and the Preservation of Genre Film Access Copies Master of Arts 2019

Adam Abouaccar

Film and Photography Preservation and Collections Management

Ryerson University

In October of 2018, the American Genre Film Archive (AGFA) announced their intention to begin preserving VHS tapes, having up to then dealt exclusively in theatrical distribution and the conservation of celluloid. This paper assesses the purported compatibility between AGFA and their proposed initiative, taking as case study their first acquisition: a collection of tapes once belonging to the late-Mike Vraney, founder and owner of "Something Weird Video." In the following pages, I will explore the roles VHS, "Something Weird," Mike Vraney and other noninstitutional actors have played in the history of genre film preservation. AGFA's distinct approach to moving image preservation will be compared against more traditional archival practices. This paper discusses subcultural legitimacy, fan culture, and the grouping of films known as "paracinema" as defined by the academic Jeffrey Sconce. AGFA's methodologies are demonstrated to be connected to the archive's origins in fandom and the Alamo Drafthouse Cinema.
\end{abstract}




\section{Acknowledgements}

First, a sincere thank you to my thesis advisor, Dimitrios Latsis, for his guidance, feedback, and having pushed me to further develop certain ideas or statements I had initially deemed to be throwaways. Some of what I am most of proud in the following pages would not be there without your help. Additionally, a big thank you to my second reader, Bruce Elder, and to my unofficial reader Aaron Pratt, who was willing to talk through my thesis when I had nothing on the page and call me out when what I had wasn't working. Dropping by your office was one of the highlights of my week.

A huge thank you to the AGFA team, Sebastian Del Castillo, Joe Ziemba, Alicia Coombs, Ivan Peycheff, Zack Carlson and Austin Miller, who were all so generous with their time, materials and specialized knowledge. Thank you for having welcomed a genre film tourist into your midst. An additional huge thank you to Marta Braun for everything these past two years, and to my colleagues at Ryerson University. And thanks to Sarah Bird, Chris Purkiss, Wyeth Purkiss and Winston for having been such incredible hosts these past six months.

Thanks to my parents for their continued, unwavering and unconditional support, and for having visited me in Austin at the halfway point. It was a very welcome distraction. Finally, and most importantly, thank you so much to my partner, Amelia Wong-Mersereau, who moved with me to Toronto so I could pursue graduate studies and had to contend with, among other things, Thailand's 12-hour time difference, crummy videocall reception, and brutal Texas heat. Looking forward to playing the role of supportive partner this coming year. 


\section{Table of Contents}

Introduction $\quad 1$

$\begin{array}{ll}\text { Chapter } 1 & 12\end{array}$

$\begin{array}{ll}\text { Chapter } 2 & 20\end{array}$

$\begin{array}{ll}\text { Chapter } 3 & 27\end{array}$

Conclusion $\quad 35$

$\begin{array}{ll}\text { Bibliography } & 38\end{array}$ 


\section{Introduction}

The American Genre Film Archive (AGFA) was founded in Austin Texas in 2009 as a manifestation of the Alamo Drafthouse's historical advocacy for preservation and presentation of celluloid film. In the ten years since the archive's inception, it has become an expansive repository of genre film release prints, elements, negatives and trailers. The collection is surprisingly diverse. 'Genre Film' as a category is not succinctly defined by AGFA, and I would argue that this is to the benefit of their collecting mandate, allowing them to take in films based on individual merit, as opposed to adherence to any rigid criteria. However, most of their collection does fall neatly within the academic purview of "paracinema," a term coined by Jeffrey Sconce to encapsulate a broad range of cinemas:

In addition to art film, horror, and science fiction films, "paracinema" catalogues "include entries from such seemingly disparate genres" as badfilm, splatterpunk, mondo films, sword-and-sandal epics, Elvis flicks, government hygiene films, Japanese monster movies, beach party musicals, and "just about every other historical manifestation of exploitation cinema from juvenile delinquency documentaries to ... pornography. ${ }^{1}$

For my purposes, "paracinema" will be a term applied to genre film with an emphasis on popular reception (read: denigration), especially by the academy and institutional powers that be. ${ }^{2}$

AGFA's celluloid holdings contain materials dating from the silent era through to the final days of $35 \mathrm{~mm}$ circulation prints in the late 2000s. In addition to their preservation work, AGFA has become a reputable digital restoration lab, and a distribution arm for numerous repertory home video labels looking to branch into the theatrical market. AGFA's evolution has been haphazard and incremental as the archive continues to take on new challenges and opportunities. In October

\footnotetext{
${ }^{1}$ Jeffrey Sconce, “"Trashing' the Academy: Taste, Excess, and an Emerging Politics of Cinematic Style," Screen 36, no. 4 (December 1, 1995): 371-93, https://doi.org/10.1093/screen/36.4.371.

${ }^{2}$ However, this has only traditionally been the case. In the past few years, the academy has arguably embraced genre film, and archives are making efforts to collect and preserve it.
} 
2018, AGFA announced their latest genre film preservation target: VHS. In the press release,

AGFA Advisory Board member Zack Carlson argues for the importance of such an initiative:

"While hundreds of thousands of movies have been made around the world over the last century or so, only a fraction of them have survived, much less been released on video or streaming[.] In many cases, the original elements are completely gone, and VHS is the last and only stop for these titles that will otherwise vanish into total oblivion."

Zack Carlson's choice of language may come across as sensational or alarmist, but his claims are certainly backed by his credentials. Carlson is on the board of directors at Scarecrow Video, one of the largest video stores and publicly-accessible collections of VHS tapes in the world. ${ }^{4} \mathrm{He}$ was also responsible for introducing a VHS format-specific monthly series, at the Alamo Drafthouse in $2011 .^{5}$

AGFA plans to begin its initiative with a collection of tapes that once belonged to Mike Vraney, founder of the home video label "Something Weird Video." Mike Vraney died in 2014. Most of the tapes in this acquisition are S-VHS masters used in the production of "Something Weird" VHS releases. These masters are often the best possible remaining elements because, in the case of many titles, the source film elements are either missing, damaged or no longer existent. I will be addressing AGFA's project from multiple points of inquiry. This paper will evaluate the significance of VHS to AGFA's broader genre film preservation mandate. It will also present the history of VHS as a medium for genre film production, distribution, and most importantly, preservation. I will lay out the resources AGFA is bringing to their initiative, and discuss the ways in which the American Genre Film Archive is re-activating and rendering accessible its digital preservations of genre film VHS tapes. Finally, I will investigate what these re-activations reveal

\footnotetext{
${ }^{3}$ Katie Rife, "The American Genre Film Archive Announces the next Stage in Its Mission: VHS!," News, accessed April 7, 2019, https://news.avclub.com/the-american-genre-filmarchive-announces-the-next-stag-1829873801.

4 "Board | Scarecrow," accessed April 7, 2019, http://blog.scarecrow.com/board/.

5 Aptly and creatively named 'Video Hate Squad.'
} 
about AGFA as a heritage institution and its origins within the Alamo Drafthouse Cinema chain. The above points of inquiry are ultimately meant to answer the following research question: What does it mean for a cultural heritage institution to preserve a historically non-institutional format like VHS tapes? And what might, or should this initiative resemble? Admittedly, one of the goals of this paper is to articulate and validate my previously-held intuition that VHS preservation can serve a higher purpose than simply generating revenue based on the format's renewed subcultural value.

A substantial amount of scholarship exists on genre cinema history and VHS, though much of it predates the founding of AGFA. Following a literature review, my research questions are addressed in three chapters. The first of these chapters regards VHS and its place within the genre film industry, from contemporaneous productions to Mike Vraney's amateur archival exploits. Chapter 1 discusses VHS' contributions to the history of genre film, as evidenced in the ways in which it has been used as a medium for distribution, production and preservation. It will also discuss the historical significance of Mike Vraney and his home video imprint, "Something Weird Video." This discussion is intended to be a case study on an exemplary genre film VHS distributor while at the same time addressing Vraney's role as a non-institutional genre film conservator.

Chapter 2 will provide an overview of the "Something Weird" S-VHS Master collection at AGFA. This chapter will outline AGFA's preservation intentions with their acquisition of over 2,500 VHS tapes and S-VHS masters from "Something Weird Video," as well as what my own role has been in this process. Furthermore, in this chapter I will discuss the tapes as both a catalogue of titles and a collection of material objects. Mike Vraney's personal archiving practices evidenced within this acquisition will be analyzed, including Vraney's bootlegging and labeling practices of non-"Something Weird" media. Chapter 2 closes with a discussion of other relevant tape 
collections under consideration for AGFA's initiative, including the personal collections of AGFA advisors Joe Ziemba and Zack Carlson, as well as the extensive library held by Scarecrow Video in Seattle, Washington.

My third and final chapter largely concerns an assessment of the compatibility between AGFA and their proposed initiative. It begins by acknowledging that AGFA is not the first archive to undertake the preservation of genre-related VHS tapes and considers the differences between AGFA's initiative and a similar but distinct 2015 project at Yale University. I argue that the ways in which AGFA's initiative differs from Yale's can inform one's understanding of AGFA's archival status, traditional or otherwise. This chapter discusses the ways in which AGFA reactivates and renders accessible its digitizations of VHS tapes, as well as what these reactivations reveal about AGFA as a cultural heritage institution and its origins within the broader Alamo Drafthouse Cinemas company. My assessment of the compatibility between AGFA's mission and VHS as a medium will be examined along ideological, logistical and historical lines. As I have already stated, much scholarship already exists on the historical relationship between genre film and VHS. My goal in the following pages is to bring these texts into conversation with one another and update the discussion to include AGFA, an institution that is still relatively young, yet ripe for further academic assessment.

A foremost consideration of my research is the role that non-institutional collectors play in the preservation of genre cinema, with a focus on the collecting, preservation and distribution practices of Mike Vraney. In A Thousand Cuts: The Bizarre Underground World of Collectors and Dealers Who Saved the Movies, filmmaker Dennis Bartok and notable film dealer Jeff Joseph dedicate a chapter to Vraney, offering insights into the illicit origins of the "Something Weird" 
archive and the many genre titles he saved. ${ }^{6}$ The book at times paints its collector subjects as martyrs, despite their having benefited substantially from their lucrative dealings; Joseph was briefly imprisoned for his activity as a film dealer.

A notable counterweight to the romanticism and aggrandizement of Ten Thousand Cuts is found in Anthony Slide's 2018 book, Magnificent Obsession: The Outrageous History of Film Buffs, Collectors, Scholars, and Fanatics. ${ }^{7}$ Slide, an amateur scholar who wrote one of the seminal books about film preservation, Nitrate Won't Wait, takes as his subject here the history of film collecting and film fandom. ${ }^{8}$ Slide is seldom overtly-charitable toward his subjects, choosing instead to highlight the deficiencies and idiosyncrasies of dedicated film buffs. Even so, the book's subject is approached from a position of clear admiration. Slide effectively traces the history of the film buff phenomenon from its innocent beginnings in the silent era to its present, somewhat mean-spirited continuance online.

Following his death, Mike Vraney was canonized by David Church in an article for The Moving Image that same year. "Something Weird This Way Comes: Mike Vraney (1957-2014)" expresses Church's reverence for Vraney as having run the home video label with the greatest contribution to preserving films outside the canon. ${ }^{9}$ Church's profile of Vraney is perhaps the definitive testament to Vraney as cultural conservator.

\footnotetext{
${ }^{6}$ Dennis Bartok and Jeff Joseph, A Thousand Cuts: The Bizarre Underground World of Collectors and Dealers Who Saved the Movies, 1 edition (Jackson: University Press of Mississippi, 2016).

${ }^{7}$ Anthony Slide, Magnificent Obsession: The Outrageous History of Film Buffs, Collectors, Scholars, and Fanatics, 1 edition (Jackson: University Press of Mississippi, 2018).

${ }^{8}$ Anthony Slide, Nitrate Won't Wait: A History of Film Preservation in the United States (Jefferson, N.C.; London: McFarland \& Co., 2001).

${ }^{9}$ David Church, "Something Weird This Way Comes: Mike Vraney (1957-2014)," The Moving Image 14, no. 2 (2014): 51-67.
} 
Another way in which VHS collecting has played in genre film preservation is addressed in Dax Sorrenti's "VHS 2.0: Amateur Archiving on the Internet and the Nostalgic Reclamation of Retro Media." ${ }^{10}$ Sorrenti discusses the abundance of a new strain of orphan media, brought about by the advent of cable television and VHS tape. Sorrenti's central argument is that the Internet has given way to a means through which amateur preservationists can archive and disseminate this material. According to Sorrenti, interest in this sort of preservation is due to a sense of nostalgic attachment to the material, not unlike popular attachment to cult films.

The nostalgic attachment to cult films on VHS and amateur efforts to preserve them is addressed in the 2013 shot-on-VHS documentary, Adjust Your Tracking. ${ }^{11}$ Featuring interviews with collectors, video store owners, filmmakers and distributors, among them AGFA-advisor Zack Carlson, the film at the very least makes a convincing argument that VHS genre cinema is not only worth preserving for its cultural significance but also its contemporary relevance.

An essential counterpoint to the romanticism and self-celebration of texts like Adjust Your Tracking is found in David Church's article for Flow, "The Untold Story of the Original, FactoryProduced, Horror/Exploitation VHS Collector," in which Church pointedly objects to the classification of these collectors as amateur archivists, in no small part because archivists are meant to provide some form of access to the materials they collect. ${ }^{12}$ Church argues that the contemporary VHS subculture is founded on an ethos of bad faith, privileging the least meritorious of movies and lowest of presentation standards. What remains is an implicit reinforcement of the importance

\footnotetext{
${ }^{10}$ Dax Sorrenti, VHS 2.0: Amateur Archiving on the Internet and the Nostalgic Reclamation of Retro Media. (Vancouver: University of British Columbia, 2012), https://central.baclac.gc.ca/.item?id=TC-BVAU-41976\&op=pdf\&app=Library.

${ }^{11}$ Matt Desiderio et al., Adjust your tracking, 2014.

12 David Church, "The Untold Story of the Original, Factory-Produced, Horror/Exploitation VHS Collector," Flow 21, no. 2 (2014), https://www.flowjournal.org/2014/11/the-untold-story-of-thevhs-collecto/?print=print.
} 
of a genre film institution to undertake what has largely been a non-institutional and problematic archival practice.

A discussion of genre film preservation would not be complete without addressing the ways in which the archive and the academy have traditionally dealt with works like those distributed by Something Weird. Eric Schaefer is a professor in Visual \& Media Arts at Boston's Emerson College, and author of Bold! Daring! Shocking! True!: A History of Exploitation Films, 19191959. In his 2005 article published in The Moving Image, "Dirty Little Secrets: Scholars, Archivists, and Dirty Movies," Schaefer discusses the complicated position occupied by adult films within the academy and archive. ${ }^{13}$ Schaefer argues that adult films are "perhaps the loneliest orphans" due to their low critical regard and questionable copyright status. ${ }^{14}$ While arguing in 2005 that the lack of preservation for these works is not due to lack of scholarly interest, Schaefer bemoans archives' unwillingness to make their adult film holdings publicly known and accessible. Schaefer namechecks "Something Weird Video" as a commercial company providing an essential preservation service, but emphasizes the ways in which their commercial status motivates their decisions. One wonders what Schaefer thinks about the activities of AGFA, which began in earnest 5 years after this article's publication.

Prior to my undertaking any research into my proposed topic, I had incorrectly assumed that AGFA's VHS preservation initiative was the first of its kind. I soon learned of Yale's own recent foray into genre VHS with their decision to welcome a collection of nearly 3000 horrorrelated tapes. This project is chronicled in the article/press release, "Horror and Exploitation on

${ }^{13}$ Eric Schaefer, "Dirty Little Secrets: Scholars, Archivists, and Dirty Movies," The Moving Image 5, no. 2 (November 22, 2005): 79-105.

${ }^{14}$ Ibid. 80. 
VHS: The History of Home Video Comes to Yale." ${ }^{\prime 15}$ The acquisition was overseen by the author of this article, Aaron Pratt, who does not work directly for Yale but is in fact UT Austin's Curator of Early Books and Manuscripts at the Harry Ransom Center. Pratt's justifications for the acquisition, and the examples he provides for its research potential, elucidate Yale's mandate and the ways in which it differs from that of AGFA. ${ }^{16}$

It is also important to concede that my thesis is not the first to take as its subject the American Genre Film Archive and its archival approach. With "Rebels, Nudie-Cuties, and Hipsters: A Study of the American Genre Film Archive," Laura Kusnierz argues that AGFA is actively rebelling against established notions of what a film archive should be, both in its practices and, more importantly, the types of work it chooses to collect and preserve. ${ }^{17}$ Kusnierz is interested in whether AGFA still meets industry criteria as an archive, despite this rebellion, and how this status affects their ability to carry out their mandate.

An important concept I will address in my thesis is that of paracinema or 'outsider cinema', as it encompasses the type of works valued by AGFA and their reasons for appreciating them. The term was first put forth in Jeffrey Sconce's article, "Trashing the Academy: Taste, Excess and an Emerging Politics of Cinematic Style," to describe an interest in lower forms of disposable cinema

\footnotetext{
15 Aaron T Pratt, "Horror and Exploitation on VHS: The History of Home Video Comes to Yale," ed. Caetlin Benson-Allott and Eugenie Brinkema, Journal of Visual Culture 14, no. 3 (December 2015): 332-35, https://doi.org/10.1177/1470412915607925.

${ }^{16}$ Pratt appears to value the carriers as artifacts, while AGFA is above all interested in the content. The two initiatives overlap in their value of what these tapes reveal about audience reception.

${ }^{17}$ Lauren Ashley Kusnierz, "Rebels, Nudie-Cuties, and Hipsters : A Study of the American Genre Film Archive” (Thesis, 2014), https://repositories.lib.utexas.edu/handle/2152/26549.
} 
(monster movies, exploitation films, adult films). ${ }^{18}$ According to Sconce, celebration of the paracinema is a political act of opposition to the status quo.

Another consideration of my research is the medium-specificity of genre cinema, as it applies to both theatrical presentation and home video. Steve Jones is a senior lecturer at Northumbria University who publishes scholarship on horror and pornography. Jones published "Preserved for Posterity? Present Bias and the Status of Grindhouse Films in the "Home Cinema" Era" in the Journal of Film and Video. ${ }^{19}$ Jones argues that, though grindhouse cinemas may be gone, the scholarly interest in them is as strong as ever. His thesis is that, because grindhouse is as much about a presentation context as it is about the films shown, the experience of grindhouse cinema cannot be recreated at home on a DVD, especially one "sanitized" by the process of digital restoration during which all filmic aspects have been removed. ${ }^{20}$ Jones dissects the problems with invoking "grindhouse" as an archival, aesthetic or nostalgic designation, but suggests that the term is still relevant to the ways in which films are and will continue to be consumed.

The subject of VHS-specificity is perhaps best addressed by Caetlin Benson-Allott, an Associate Professor of English and Film and Media Studies at Georgetown University. In her book, Killer Tapes and Shattered Screens: Video Spectatorship from VHS to File Sharing, Benson-Allott explores, with an emphasis on genre film, how cinema's ongoing platform and distribution changes since the late 1970s have affected both filmmaking form and audience reception. ${ }^{21}$ Benson-Allot's argument is straightforward and well-supported by examples spanning the history of the horror

\footnotetext{
${ }^{18}$ Jeffrey Sconce, "'Trashing' the Academy: Taste, Excess, and an Emerging Politics of Cinematic Style," Screen 36, no. 4 (December 1, 1995): 371-93.

${ }^{19}$ Steve Jones, "Preserved for Posterity?: Present Bias and the Status of Grindhouse Films in the 'Home Cinema' Era,' Journal of Film and Video 70, no. 1 (February 21, 2018): 3-16. ${ }^{20}$ Ibid. 4.

${ }^{21}$ Caetlin Anne Benson-Allot, Killer Tapes and Shattered Screens: Video Spectatorship from VHS to File Sharing (Berkeley: University of California Press, 2014).
} 
genre, though it becomes more tenuous as she moves away from physical media towards the influence of the Internet. Her book has been most valuable for my research due to its formal analysis of the films of George A. Romero. Benson-Allot demonstrates the ways in which Day of the Dead (1980), shot in 35mm and released in cinemas, was designed and photographed with an eventual VHS release in mind.

Lucas Hilderbrand's Inherent Vice: Bootleg Histories of Videotape and Copyright examines analog home video from a legal perspective. ${ }^{22}$ The format was introduced to consumers as a bootleg-ready blank tape. This resource is most important for introducing an 'aesthetics of access,' which contends that the medium specificity of the videotape becomes most apparent through repeated duplication, wear and technical failure. The text also presents a telling case study regarding VHS's impact on film preservation: the underground duplication and circulation of Todd Haynes' Superstar: The Karen Carpenter Story (1987) on tape after the film was pulled from distribution.

Finally, my research has examined VHS as a commodity object. This subject is notably addressed in From Betamax to Blockbuster. ${ }^{23}$ Joshua Greenberg traces the shifting function and importance of the VCR in the family home from its introduction. According to Greenberg, the VCR, in combination with the video store, transformed movies from an experience into a commodity, and furthermore changed the ways in which movies were produced and distributed.

Similarly, Daniel Herbert's 2014 book, Videoland examines the ways in which the emergence of the video store recontextualized movie consumption as the purchase and collection

\footnotetext{
${ }^{22}$ Lucas Hilderbrand, "Inherent Vice: Access, Aesthetics, and Videotape Bootlegging" (Ph.D., New York University, 2006), http://search.proquest.com/docview/305294367/abstract/6BB7E8E3D86A4A0EPQ/1. ${ }^{23}$ Joshua M. Greenberg, From Betamax to Blockbuster (Inside Technology): Video Stores and the Invention of Movies on Video (Cambridge, Mass.; London: MIT Press, 2010).
} 
of material goods. ${ }^{24}$ Herbert further demonstrates the ways in which various types of video stores adhered to different organizational politics, with some prioritizing novelty and others minutely classifying by specialized sub-genres. In the second part of Videoland, Herbert profiles a number of these specialty video stores, including Seattle Washington's Scarecrow Video, a minor case study in my research.

Herbert has also demonstrated an interest in the role VHS plays in contemporary genre film distribution. Taking its name from one of the earliest home video distributors in the United States, Daniel Herbert's "Nostalgia Merchants" examines the recent phenomenon of distribution companies confronting the contemporary video-streaming paradigm with the release of limitededition VHS tapes. ${ }^{25}$ Herbert argues that this VHS revival forces a reevaluation of our relationship to video commodities and contemporary movie culture more generally. The author discusses recent scholarship on video as a distinct medium from film. He then goes on to examine the continued success of VHS within the context of paracinematic appreciation. Herbert's text has been instrumental to my assessment of AGFA's approach to presentation of VHS.

${ }^{24}$ Daniel Herbert, Videoland: Movie Culture at the American Video Store, First edition (Berkeley: University of California Press, 2014).

${ }^{25}$ Daniel Herbert, "Nostalgia Merchants: VHS Distribution in the Era of Digital Delivery," Journal of Film and Video; Englewood 69, no. 2 (Summer 2017): 3-19. 


\section{Chapter 1}

In addition to the promise of financial gain through continued releases, institutional authorities have traditionally preserved films because they are deemed historically, culturally or aesthetically significant, and as such should be made continually accessible to future generations. ${ }^{1}$ Genre film history was largely written alongside but outside academic and archival institutions, with less-privileged access to screening materials due to traditionally neglectful preservation. Numerous genre film titles in the first half of the $20^{\text {th }}$ century were exhibited on celluloid to the point of total deterioration; many later works never received a theatrical release, and were only made accessible on videotape. This is all to say that archival film prints of genre film titles are particularly rarefied commodities among film collections.

Of the thousands of genre film titles that would otherwise be lost were it not for VHS, there are no doubt some that bear significance to the history of genre cinema, and should for this reason be preserved while the opportunity is still materially available. However, with this chapter I seek to argue for the significance of VHS as a format to the history of genre film, elucidating AGFA's mission to actively address its preservation. This chapter will make a case for the format's contributions as a tool for new forms of distribution, production, and preservation. This chapter will also discuss Mike Vraney, an ex-manager of punk bands, who within the context of the VHS market became one of the most successful businessmen, and one of the most crucial conservators, of the early home-video era.

\footnotetext{
1 “About This Collection | Selections from the National Film Registry | Digital Collections | Library of Congress," Digital Collection, Library of Congress, Washington, D.C. 20540 USA, accessed June 4, 2019, https://www.loc.gov/collections/selections-from-the-national-filmregistry/about-this-collection/.
} 
The new availability of genre film titles afforded by VHS contributed significantly to the forging of genre film fandom and the writing of genre film history. Moreover, the means through which content is packaged, stocked and provided to the consumer allowed the format greater reach than other formats before it. With the advent of VHS, genre film titles that otherwise might not screen outside major cities, especially if local cinemas did not deem it viable at the box office, could now be seen. Furthermore, those titles that once might only enjoy short runs at specialty theaters were now made continuously available, allowing a diffuse fandom to accumulate over time.

A key distinction between VHS and theatrical presentation is of course spectatorship. VHS is a medium that enables easy private viewing, privileging the enjoyment of culture's more abject content (workout videos, pornography, and genre film) in the comfort of one's home. ${ }^{2}$ This privacy allowed viewers to enjoy traditionally stigmatized content without its cultural baggage. Furthermore, VHS removed paracinema from the spaces in which it was traditionally enjoyed, grindhouse theaters and porno theaters, making content available to those unwilling to frequent such spaces.

Another paradigm shift brought about by the introduction of VHS was the conversion of films as communal experiences to films as commodified objects to be possessed. This shift feeds into genre film's intersections with histories of fandom, consumption and collecting. As for the video store itself, a basic yet crucial way in which it has contributed to genre film history has been

\footnotetext{
2 The connection between VHS and private viewing is explored at length in Peter Alilunas' excellent book on the history of adult video, Smutty Little Movies: The Creation and Regulation of Adult Video (Berkeley: University of California Press, 2016).
} 
in the way in which it organizes material. Video store sections contributed to the definition and delineation of subgenres as they continue to be understood today. ${ }^{3}$

VHS ultimately shaped genre film history by making works available to those wanting to see them, discuss them, and write about them. Whereas other forms of cinema, including those in the established arthouse canon, have historically benefited from their presence in the programming rotation of cinematheques and repertory theaters, genre film did not receive the same treatment, and this necessitated another space for its growth and dissemination. This new form of distribution also sparked a need for increased genre film production. The video store contributed directly to the proliferation of genre film titles due the new market it created. Video store shelves would go on to be stocked with budget-conscious, hastily produced films engaging with topical subjects and variations on common themes. In this way, the video store privileged genre cinema over other cinemas.

In addition to catalyzing production, VHS also guided the aesthetics of genre film productions during its period. In her book, Killer Tapes and Shattered Screens: Video Spectatorship from VHS to File Sharing, Caetlin Benson-Allot takes the zombie films of George A. Romero as a case study. Discussing Day of the Dead (1980), Benson-Allot demonstrates that, though the film was shot on 35mm negative, Day of the Dead employs composition and a colour palette conducive to their subsequent replication on television screens. She argues that Day was the first of Romero's zombie films to do so. This is notable because Day was also the first of Romero's zombie films made during the home video era. The crux of her argument is that the

\footnotetext{
${ }^{3}$ They can also be said to have helped foster fandom by providing further viewing recommendations in a given genre to "newcomers." Although the video store has been rendered almost completely obsolete by streaming platforms, its approaches to organization and recommendations have persisted in the form of subgenre tags upon which algorithms like that of Netflix rely to draw connections between media, and deliver curated content.
} 
genre film industry's new investment in video, and its viewership, influenced Romero's new style.

In addition to shot-on-film genre films with the home video or TV broadcast market in mind, there is the large body of direct-to-videotape work shot on video for home video release. Shot-on-VHS horror is a substantial and significant part of genre film history and is one of the key motivators for AGFA's preservation efforts. Interestingly, in this instance, VHS access copies are not low-fidelity byproducts of a distribution line. Rather, they are every bit an archival format as theatrical circulation prints are to titles shot on film and meant for theatrical release. ${ }^{5}$

Duplication has historically been a principal form of motion picture preservation, and it is worth noting for my purposes that VHS was first released to the public as a tool for duplication: a blank tape could be used to make unauthorized copies of material for sharing and distribution. Though I am not arguing that bootlegging necessarily privileged genre cinema over other cinemas, VHS did, perhaps inadvertently, contribute to the survival of numerous genre film titles, doing much of the work that institutional archives have for more mainstream works. Famous examples of titles benefitting from the illicit circulation of bootlegs include Todd Haynes' Superstar: The Karen Carpenter Story (1989) and Andrzej Żuławski’s Possession (1981), the latter of which has in the past decade benefitted from immense newfound popularity and critical re-evaluation. VHS bootlegs functioned as holdover supports for genre films, preserving them between their initial release and acceptance into institutions and the broader public consciousness. That said, much work remains to be done on the preservation of paracinema in the aftermath of its legitimation. In

\footnotetext{
${ }^{4}$ Earlier in her book, Benson-Allot cites as an additional example the opening titles of Sean Cunningham's Friday the 13th, a film first released on $35 \mathrm{~mm}$, in which the title card appears to break through glass, a cinematic stand-in for the television screen.

${ }^{5}$ A note that the term archival is used here to mean "serving archival value," rather than permitting long-term reliable storage and protection.
} 
addition to VHS's contribution as an inadvertent tool for genre film preservation, the format also created a new market for repertory genre film releasing. In some cases, projected profits from VHS releases directly motivated the preservation of countless genre films. An exemplary case study of this relationship is found in what Mike Vraney did through "Something Weird Video."

It is worth equating VHS preservation's potential contribution to the future of genre film history with what $16 \mathrm{~mm}$ reduction prints have come to mean for the writing of early-film history. In the late 1920s, distributors like Kodascope, Bell \& Howell and Universal produced 16mm safety copies of silent films for home viewing. These prints, though discernibly inferior in quality, preserved the content of their $35 \mathrm{~mm}$ nitrate sources, becoming, in some cases, our only link to certain titles. The effect of this, as noted by Jan-Christopher Horak in his text "Archiving, Preserving, Screening 16mm," is that these $16 \mathrm{~mm}$ prints are now treated as original masters from which $35 \mathrm{~mm}$ dupe negatives and prints have subsequently been generated. ${ }^{6}$ Many of these titles have since found their way to DVD through projects like Flicker Alley's Saved from the Flames box set and Ben Model's Accidentally Preserved series.

"Something Weird Video" began in earnest as a mail-order distribution outfit in 1990. Based out of Seattle, WA, "Something Weird" initially dealt in illicit bootlegs of exploitation and sexploitation films, relying on magazine ad-space and word-of-mouth among collectors for promotion. In a 2012 interview for the Third Eye Cinema podcast, Vraney cites a network of collectors and enthusiasts who began circulating and trading content taped off television at the beginning of the 1980s as an inspiration for the company. The foundational collection of Vraney's bootlegging operation was composed of ten features on $16 \mathrm{~mm}$ and $35 \mathrm{~mm}$ film, purchased from a

\footnotetext{
${ }^{6}$ Jan-Christopher Horak, “Archiving, Preserving, Screening 16mm," Cinema Journal 45, no. 3 (July 31, 2006): 112-18.
} 
dealer in Dallas, TX that he then had transferred to videotape. Vraney would go on to acquire large collections of exploitation film elements through various circumstances, from abandoned warehouses and the back rooms of antique shops. Realizing that an eventual crackdown on outfits such as his was unavoidable, especially as VHS distribution proved to be so profitable for repertory films, Vraney transitioned from distributing bootlegs to buying elements and titles from filmmakers outright. Regarding his motivations, Vraney's interest in the sexploitation subgenre dates to his time as a projectionist and cinephile. His desire to focus on distributing such material however primarily stemmed from what he perceived to be an untapped market. As he noted in an interview in 2012, "by the late 80s, I'd figured out, video had been around 10+ years, and there was no more than a hundred sexploitation movies in the marketplace, that included Russ Meyer's."7

What makes "Something Weird" so interesting from a curatorial standpoint, especially given contemporary discourses around moving image assets worthy of preservation, is Vraney's demonstrated interest in films falling outside the compass of narrative feature filmmaking. In his article, "Something Weird This Way Comes," David Church provides a succinct yet comprehensive overview of Vraney's curatorial inclinations:

\begin{abstract}
Strolling through the company's catalog reveals a glimpse of the thousands of films that Vraney rescued from historical obscurity and made available to a paying public: from the company's primary specialization in American exploitation, sexploitation, and hardcore adult films to its smaller collections of African American race films (by Oscar Micheaux, Spencer Williams, and others), 1930s-1940s American B-films, 1960s-1970s European and East Asian genre films (e.g., pepla, krimis, spy movies, Italian westerns), and all manner of ephemeral and nontheatrical short subjects, including striptease loops, soundies, educational films, industrials, and other forms of so-called useful cinema. ${ }^{8}$
\end{abstract}

\footnotetext{
${ }^{7}$ Mike Vraney, interviewed in BigPoppaOnline, Third Eye Cinema podcast, May 6, 2012, http://www.blogtalkradio.com/bigpoppaonline/2012/05/06/third-eye-cinema-5612-with-mikevraney.

${ }^{8}$ David Church, "Something Weird This Way Comes: Mike Vraney (1957-2014)," The Moving Image 14, no. 2 (2014): 53.
} 
This interest in ephemeral and nontheatrical short subjects mirrors the rise of orphan films in contemporary preservation discourse. Vraney's packaging of these works took two forms: compilation tapes or supplemental features. Vraney would invariably use two-hour master tapes for "Something Weird" releases, and would always be sure to use the whole tape. This is to say, if a film's running time was shorter than 120 minutes, the supplemental time on the tape would be allotted to orphaned oddities and curiosities as "bonus" features. ${ }^{9}$ This is another way in which the material limitations and allowances of VHS, through curatorial vessels like "Something Weird Video," inadvertently contributed to the preservation of other paracinematic forms.

This portrait of the film dealer as idealistic preservationist is by no means new. In fact, Mike Vraney was proud and forthcoming about the fact that he regarded himself first and foremost as a "conservator." And though he made his living through the distribution of access copies, Vraney was not a lo-fi fetishist. A quality product was essential to the "Something Weird" ethos. On the cover of an original "Something Weird" catalogue preserved in AGFA's paper archive, Mike Vraney introduces the company in the following way:

SOMETHING WIRD VIDEO, your curator and conservator of the nation's consummate collection of eclectic exploitation and sexploitation movie videotapes is proud to announce our 1993 Fall release of 120 new titles (we've been busy little beavers over the summer) all first-time-on-video, all transferred from their ORIGINAL 35mm negative or print. So don't be shy, just dig into our "SEX FEAST" of thought-to-be-lost FILM DELIGHTS. Happy Hunting! - MIKE VRANEY, S.W.V. ${ }^{1011}$

If making films accessible and valuing ethical presentation practices are not enough to consider one a conservator, Vraney's credentials remain cemented by the many titles he physically saved

\footnotetext{
${ }^{9}$ Including this type of supplemental material recalls the double bill and mixed program practices of second-run theatres in 1950s and 1960s, the period during which many eventual "Something Weird" titles were first released.

${ }^{10}$ Something Weird Video, Fall 1993 Catalogue (Seattle, WA: Something Weird Video, 1993).

${ }^{11}$ Elsewhere, in the interview for Third Eye Cinema, Vraney expresses his love of negative, analogizing it to possessing the actual painting in place of lithographs.
} 
from destruction. In their book, A Thousand Cuts: The Bizarre Underground World of Collectors and Dealers Who Saved the Movies, Bartok and Joseph depict a thrilling scene from the origin story of "Something Weird," in which Vraney and co-conspirator Frank Henenlotter have broken into the abandoned East Coast Movielab, once one of the busiest film labs in New York City. ${ }^{12}$ Limited only by what they could physically remove, Vraney and Henenlotter rescued the negatives to 130 titles, which they subsequently transferred to videotape for distribution.

"Something Weird" may violate some rigorous definitions of what a film conservator is because the company was and continues to be a for-profit venture, dealing strictly in access copies and prioritizing titles with profit potential. However, it is fair to argue that through its use of videotape "Something Weird" merely commercialized what had historically been a noninstitutional area of motion picture preservation. In the process, Vraney salvaged a colossal body of film history, until libraries, archives, and specialized organizations like the American Genre Film Archive were ready to "institutionalize" its custodianship. Over the past ten years, AGFA has not only become the institutional repository for the type of cinema Vraney championed, it is also actively working to preserve his legacy. Having acquired a substantial portion of Vraney's materials following his death, the American Genre Film Archive now houses "Something Weird" elements ranging from $35 \mathrm{~mm}$ negatives to VHS bootlegs. That AGFA appears to value the tape as much as it does the celluloid is cause for a deeper inquiry.

${ }^{12}$ Dennis Bartok and Jeff Joseph, A Thousand Cuts: The Bizarre Underground World of Collectors and Dealers Who Saved the Movies, 1 edition (Jackson: University Press of Mississippi, 2016), 209. 


\section{Chapter 2}

Following the death of Mike Vraney, "Something Weird" has continued to operate under the leadership of his wife and partner, Lisa Petrucci. The home video label has however sold off parts of its inventory since 2014. In July of 2018, The American Genre Film Archive acquired a number of film prints from "Something Weird," as well as their entire VHS archive. The VHS collection contains just over 2500 tapes, the majority of which are original S-VHS masters used in the production of "Something Weird" VHS releases. In addition to the masters, the acquisition contains Mike Vraney's personal tape collection, including home recordings he made of televised content.

At the start of my residency with AGFA, one of my first tasks was to compile a rudimentary catalogue of the "Something Weird" tape acquisition. At the time that I began working on the collection, AGFA's spreadsheet accounted for approximately one fifth of the total acquisition. I was tasked with noting the titles, collection ("Something Weird” S-VHS, Mike Vraney's personal tapes) and condition (presence of mould) for the remainder of the tapes.

This chapter will evaluate the "Something Weird" VHS archive as both a catalogue of titles and a collection of objects, assessing both its curatorial scope and material qualities. Additionally, this chapter will lay out the American Genre Film Archive's technical VHS preservation workflow and long-term storage strategies. I will close with a discussion of other VHS collections beyond the "Something Weird" collection that AGFA has deemed worthy targets for their preservation initiative.

As the "Something Weird" Video catalogue has grown in terms of reputation and number of titles, so too has the label's association with certain filmmakers. Directors featured prominently among the S-VHS masters in the SWV acquisition include Herschell Gordon Lewis, Doris 
Wishman, Joe Sarno, and Ed Wood. Aside from the work of American "genre auteurs," the "Something Weird" collection is rich in European sleaze, Brazilian horror (Coffin Joe, Ivan "The Terror" Cardoso), and pornography of varied types (loops, stag films, peepshows, nudie cuties, roughies, hardcore, etc). Less esoteric titles include 1950s horror and science-fiction, sword \& sandal films, and Japanese monster movies.

These titles form an expansive and comprehensive portrait of the label, but it is also worth considering the ways in which "Something Weird" VHS titles were packaged and marketed. One example of the label's distinct approach was the use of sublabels through which films were presented by notable filmmakers and genre film fans. Sublabel presenters included producer Harry Novak (Box-Office Bonanza, Harry's Horrible Horrors, Haystack Honeys), filmmaker David Friedman (Roadshow Rarities), filmmaker Frank Henenlotter (Sexy Shockers), and musician Johnny Legend (Untamed Video). Endorsement by established figures in the world of exploitation film signaled to clients what they could expect from a certain type of "Something Weird" release, especially when considering an obscure or unknown title. Other niches are more ill-defined in terms of established subgenres but group films by target audience or thematic content, as with "All Black Cast Classics," or "Sons of Hercules Theatre."

The collection also contains a significant number of compilation tapes, on which trailers, film clips, shorts and loops are packaged together by theme and sold as a single release. For the most part, these compilation tapes are branded as 'shows,' as in "Super Horrorama Shriek Show," "Dust to Dawn Drive-In Trash-O-Rama Show," "Crime Wave U.S.A. Gangsterama Show,” and "Super Atomic Sci-Fi Thrill-O-Rama Show." More than just a collection of titles, the "Something Weird" VHS archive can be read as a set of idiosyncratic curatorial choices. 
AGFA's "Something Weird" VHS acquisition can also be read as a series of material artifacts, revealing much about the home video label and its founder. Many of these tapes include notes regarding the source format used for the transfers $(16 \mathrm{~mm}, 35 \mathrm{~mm}$, negative, print). The tapes' cases offer insights into the label's aesthetic inclinations and brand identity (dayglo-coloured artwork). Furthermore, the presence of liner notes written by the likes of Eric Schaefer and Stephen Flacassier indicate the important (if peripheral) role genre film scholars played in the company's development.

The most apparent connection between the objects and their previous owner is Vraney's handwriting, present in some way on almost every S-VHS master and home-recorded tape in permanent marker. ${ }^{1}$ Vraney had an idiosyncratic cataloguing practice, best evidenced by a substantial collection of bootlegged Japanese television shows: each tape is aptly labeled “JAPANESE SUPERHERO TV" or "JSTV," followed by a sequential number and list of included episodes. As far as I can determine, these JSTV tapes were produced for his personal viewing. Included in this collection are tapes from other video labels that dealt in fare similar to that of "Something Weird," like Sinister Cinema, out of Medford, OR and The Fang, from Floral Park, NY. The presence of these tapes in the collection demonstrates Vraney's patronage of what were essentially his competitors. Another indication of Vraney's personal film consumption is found in the collection's bootlegged tapes which elucidate Vraney's eclectic personal tastes; a telling example of this is a tape containing a televised ABBA concert in full, followed by Gamera: Super Monster (1980).

\footnotetext{
${ }^{1}$ The tapes' handwritten titles suggest that Vraney may have been dyslexic, as many of them are misspelled.
} 
Many Vraney releases in the collection predate the formal incorporation of "Something Weird." These tapes are unbranded, instead featuring high-contrast black and white renderings of original poster art, laid out in a fashion reminiscent of zines. Though intended for commercial purposes, many of the tapes appear to have been illicitly produced and likely recorded off television. This theory is supported by the presence of TV guide clippings affixed to the tapes themselves as a sort of label.

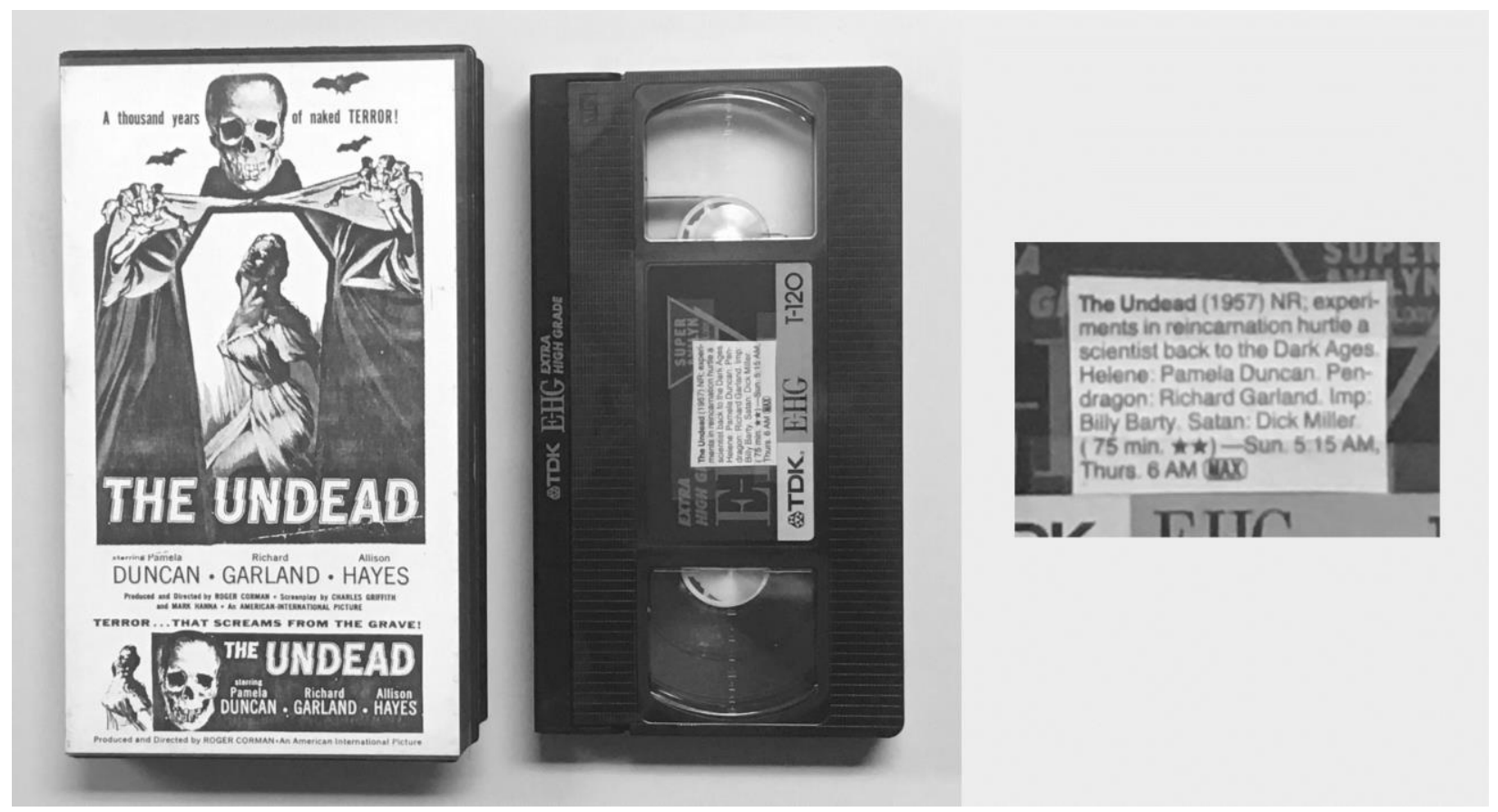

Fig. 1 Example of a pre-“Something Weird” Vraney release

While the tapes' value as artifacts make them worthy of preservation for their role in genre film home video history, AGFA is not so much a museum as it is a moving image archive, and their foremost interest in the tapes is what can be preserved that has not already been saved elsewhere. AGFA's VHS preservation project is largely a digitization initiative. Their current VHS preservation technical workflow is streamlined, requiring limited hardware and software. After a tape has been catalogued into their internal database, the archivist prepares it for digitization. 


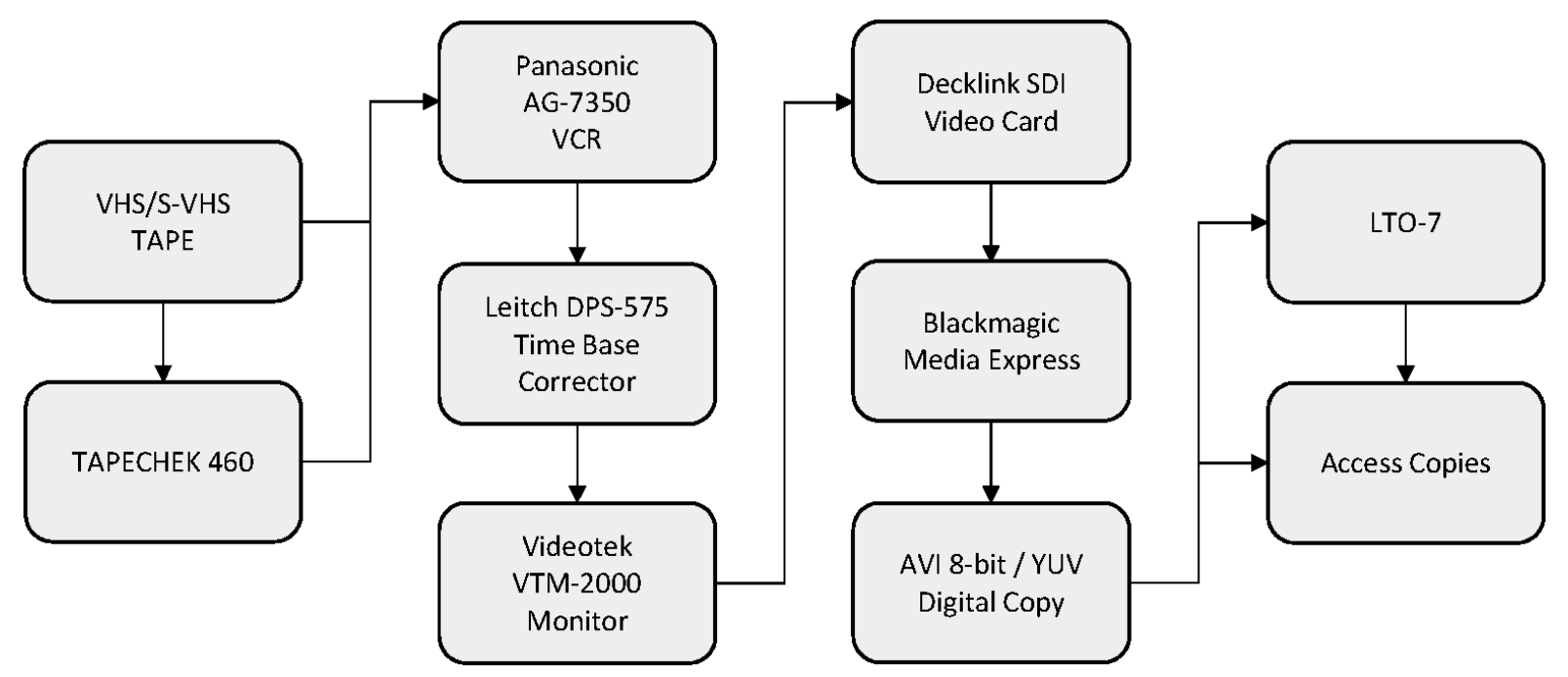

Fig. 2 AGFA's VHS Digitization Workflow

If necessary, the tape is cleaned using a TAPECHEK 460. Tapes are cleaned not only for smoother playback but also to preserve AGFA's equipment, as accumulated dust or mould can be harmful. The tape is then played back on a Panasonic AG-7350 videocassette recorder, which supports both S-VHS and VHS formats. The video signal from the VCR outputs via S-Video to a Leitch DPS-575 time base corrector (TBC) to ensure a smooth, error-free capture. From there, the TBC outputs to a Videotek VTM-2000 multiformat on-screen monitor via SDI whose purpose is to provide the archivist with the video scopes necessary to confirm that colours are being properly captured (there is minimal, if no additional colour grading). Finally, the signal is fed to a computer's Blackmagic Design Decklink SDI 4K video capture and playback card. AGFA's preferred capture software is Blackmagic's proprietary Media Express. They also have a preferred codec for VHS preservation, which is AVI 8-bit in YUV colour space. In AGFA's experience, resulting feature-length transfers are approximately $90 \mathrm{gb}$ in size. The digitized file is subsequently used to make digital access copies; the archive does not have a preferred codec for access copies, instead they cater to the specific needs of the client. The digital files are kept on LTO-7 tapes for long-term storage. 
I believe AGFA's workflow could potentially be adjusted to a more portable setup, composed of little more than a laptop, VCR, and a TBC. Scopes are desirable but not essential to the workflow, so the VTM 2000 could be omitted. A smaller, portable setup could then travel to remote sources, eliminating the need to transport tapes to Austin for on-site digitization. ${ }^{2}$ This consideration is of high importance as AGFA looks to other collections beyond the "Something Weird" archive.

AGFA-advisor Zack Carlson began seeking out possible tape sources prior to the archive's formal announcement of their VHS initiative, specifically looking for titles otherwise not available on any commercial format. Carlson has so far looked to the personal archives of collector friends and colleagues and to Scarecrow Video in Seattle, which has widely been called the greatest video store in America. Carlson has supported my research by offering access to two spreadsheets, one of which contains an internal list of Scarecrow Video's entire VHS collection, and a spreadsheet produced by Carlson, detailing tapes he has sourced elsewhere.

At the time of my writing, the Scarecrow Video catalogue contains a staggering 14552 titles on VHS, though the number of titles that would fall under AGFA's preservation purview is not known. Conversely, Carlson's spreadsheet of tapes sourced outside of Scarecrow Video contains 276 titles. This spreadsheet is highly curated, and every title has been deemed essential to the AGFA initiative. Carlson's spreadsheet is composed primarily of tapes from his and Joe Ziemba's personal collections. Indicative titles include Alien Force (1996), Death to the Pee Wee Squad (1987), Hamburger: The Motion Picture (1986), and Vampires on Bikini Beach (1988). The Scarecrow Video spreadsheet's fields are limited to item number, title, genre, and store location,

\footnotetext{
${ }^{2}$ If an AGFA archivist is unable to travel with the equipment, a remote non-AGFA technician would need to adhere to predetermined digitization standards to ensure quality control. FADGI guidelines may provide a helpful model to follow.
} 
whereas Carlson's level of description is more akin to that of an encyclopedia. It is worth mentioning here that Carlson is a prolific genre film historian in his own right, perhaps most notable for his reference book Destroy All Movies!!! The Complete Guide to Punks on Film. ${ }^{3}$ Carlson's personal spreadsheet notably provides the original shooting format for each title. AGFA has not determined whether the latter will impact which titles are prioritized, though in the case of VHS titles shot on video, AGFA will be able to digitize them with the confidence that there are no better elements potentially available.

That Zack Carlson is targeting private collections and video stores for potential elements reinforces the essential role VHS enthusiasts and video stores have played in the preservation of these titles, especially in the absence of institutional custodianship. In many ways, AGFA is simply providing legitimacy and resources to longstanding amateur and commercial efforts that began at the format's introduction and have continued ever since.

${ }^{3}$ Zack Carlson and Bryan Connolly, Destroy All Movies!!!: The Complete Guide to Punks on Film (Seattle, Wash.: Fantagraphics Books, 2010). 


\section{Chapter 3}

Having outlined in the preceding chapters the scope and significance of the "Something Weird Video" tape collection, as well as AGFA's intended technical approach to this project, I now find it crucial to offer some assessment of the "fit" between The American Genre Film Archive and genre film VHS tapes. I have put forth the arguments for the format's significance to genre film history and its legitimacy for preservation, and now a case of equal weight must be made for The American Genre Film Archive. This chapter will compare aspects of AGFA's archival approach against more traditional archival practices. It will also discuss the ways in which AGFA reactivates and renders accessible its preserved tapes, as well as what these reactivations say about AGFA, its origins in fandom, and its historic affiliation to the Alamo Drafthouse. This chapter will furthermore present the ways in which the limitations and opportunities afforded by AGFA's distinct archival status dictate their approach to moving image preservation and the surrounding discourse.

My assessment of whether it is appropriate for an archive like AGFA to undertake such a preservation initiative begins with a comparison to a possible alternative. Even though its coverage in leading fan blogs and websites afforded AGFA's 2018 announcement of their VHS project greater recognition among its intended audience than others before it, AGFA is not the first cultural heritage institution to have expressed interest in preserving the format, or to have acted on this intention. In 2015, Yale University had already announced that it acquired for preservation a large collection of horror and exploitation VHS tapes. In a press release, Aaron Pratt, the scholar and curator who spearheaded the acquisition, articulated its value:

The nearly 3,000 tapes [...] have been selected to support research on individual titles, genre, and the development of the prerecorded video industry. Trailers, cover art, box copy, and other tape-specific content provide invaluable evidence toward a richer and more nuanced account of the changes home video brought to the world of motion pictures. In addition, many of the titles in the collection remain available only on VHS. [...] Some tapes 
include violence and sexual content that are otherwise unavailable, and others contain sanitized versions that recent distributors have decided against reproducing. ${ }^{1}$

The announcement was soon followed by a symposium at the university, "Terror on Tape," in which many of the leading academics on genre film VHS presented, including David Church and Caetlin Benson-Allot. ${ }^{2}$

Pratt's justification for the acquisition is articulated here for both the interested public and the university supporting it, foregrounding the collection's academic and research potential as a grouping of artifacts. And though the American Genre Film Archive has made its materials available to me throughout my residency with them, they are by no means an institution tailored for or primarily interested in providing research and reference services. The physical tapes and their tape-specific content are secondary, if not inconsequential to AGFA's intended mission. AGFA has traditionally prioritized content, and is willing to negotiate the material needs of its carrier. At the close of Pratt's press-release he describes the Yale acquisition as "one step toward safeguarding a paradigm-shifting moment in the history of motion pictures." Conversely, the American Genre Film Archive is preserving VHS with an interest in updating the paradigm for contemporary audiences, distancing the format from its historical viewing environment and asserting its newfound "subcultural legitimacy" as an object of hip cinephilia. Whereas the Yale project is in many ways an olive branch extended by the academy to a maligned subculture, its AGFA counterpart is a case of subcultural insiders working with institutional tools.

\footnotetext{
${ }^{1}$ Aaron T Pratt, "Horror and Exploitation on VHS: The History of Home Video Comes to Yale," ed. Caetlin Benson-Allott and Eugenie Brinkema, Journal of Visual Culture 14, no. 3 (December 2015): 334.

2 "Terror on Tape: An Interdisciplinary Symposium on the History of Horror on Video | Yale University Library," accessed June 4, 2019, https://web.library.yale.edu/news/2016/04/terrortape-interdisciplinary-symposium-history-horror-video.
} 
AGFA's VHS initiative was announced during a time of peak-resurgence for the format, both within fan culture and within the archive's parent organization, the Alamo Drafthouse. At the time of this paper's writing, the Alamo Drafthouse is actively trying to resurrect the concept of the video store in Raleigh, NC. This prototype was designed to be a repository from which genre film VHS tapes can be enjoyed on-site or borrowed at no cost. ${ }^{3}$ The store's name is lifted from a monthly Alamo Drafthouse screening series of VHS-only genre films, Video Vortex. This series is currently curated by AGFA's director, Joe Ziemba, though it was first introduced by AGFAadvisor Zack Carlson. Initially entitled Video Hate Squad, the series began two years after the founding of AGFA. The presentations were initially restricted to a single cinema due to the event's setup: a VCR placed at the front of the theater, from which an actual VHS tape played, connected to a projector in the booth. The series is now part of the Alamo Drafthouse's "national packet," meaning multiple cinemas within the chain host screenings of the same, predetermined title monthly. Physical tapes are no longer used for the presentations as content is now digitized and made available to cinemas on a disc or hard drive.

There is substantial overlap between Video Vortex the series and the American Genre Film Archive's mission and collections. In addition to the fact that Ziemba is both AGFA's director and the series' curator, Video Vortex is one of the primary dissemination platforms for the archive's latest VHS preservations. Another way in which AGFA reactivates preserved VHS is through their home video label. In addition to Blu-ray releases produced from $16 \mathrm{~mm}$ and $35 \mathrm{~mm}$ film elements, AGFA intermittently releases VHS-only genre films on DVD, in partnership with Joe Ziemba's other venture, "BLEEDING SKULL!." Titles have included Blood Lake and The Soultangler, both

\footnotetext{
${ }^{3}$ For clarification, the tapes made available at this and subsequent Video Vortex stores are not the same being actively collected by the American Genre Film Archive for their preservation initiative.
} 
initially released in 1987. In addition to being a video label, "BLEEDING SKULL!" is a blog through which Ziemba and his colleagues promote VHS as a format, films produced with it as a shooting medium, and the many titles on VHS still unavailable on other formats. "BLEEDING SKULL!" is not strictly a VHS-related blog, though its debt to VHS as a medium for production, access and discovery is clear. According to its "About" page, "BLEEDING SKULL!" was launched with the intent to "unearth no-budget horror and exploitation films and foster an appreciation for what they really are: triumphs of unfettered ambition and creativity."4 "BLEEDING SKULL!" has released titles on both DVD and limited-run VHS tapes. For its part, the Alamo Drafthouse has in recent years also released repertory and contemporary titles on the obsolete format, including Heavy Metal Massacre (1989) and The Connection (2014). The Alamo Drafthouse is planning an annual VHS-centric festival in addition to their video store project.

The Video Vortex series is notable because of the way in which it conflates home video and cinematic apparatuses. Video Hate Squad initially employed actual tapes and a VCR in a theatrical setting. As a result, screenings were potentially subject to the unique technical follies of the format, drops in signal fidelity, tracking issues, which are not the same material complications posed by the celluloid or digital presentations that otherwise occurs in such screenings. The decision to place the VCR at the front of the cinema, as opposed to concealing it in another room out of view, renders its manipulation and possible troubleshooting a visible component of the moviegoing experience. One of the ways in which Video Vortex presentations consistently violate the VHS-viewing experience is the sheer scale of the images: even disregarding VHS-only filmmakers' intentions, it remains a safe argument that these films were not typically viewed at a height of 40-to-50-feet at the time of their emergence. Additionally, as these films were never

4 “About - BLEEDING SKULL!,” accessed June 4, 2019, http://bleedingskull.com/about/. 
given a theatrical release, they did not traditionally play such large audiences at any one time. In essence, AGFA and the Alamo Drafthouse have fundamentally distanced these presentations from historical and traditional viewing practices. ${ }^{5}$ This can be a troubling notion given the fact that film preservationists endeavor to remain faithful to the way in which the materials were first exhibited. I would argue that AGFA's deviation from faithful presentation here is not an example of poor archival practice. Rather, it is one of the ways in which AGFA incorporates genre film's tradition of non-institutional custodianship into their approach, foregoing negotiable archival concerns in favor of financial viability.

That Video Vortex screenings are now presented from a digital VHS transfer is worth discussing. This change was made for logistical purposes once the series migrated to other Alamo Drafthouse locations, though it also signals a turn away from the materiality of VHS. Elsewhere, within AGFA and the Alamo Drafthouse but outside the theaters themselves, the VHS tape's materiality remains foregrounded. Whereas a digital presentation of content transferred from an obsolete format can be said to assert the content itself over its original source, foregrounding an archaic carrier's function and mechanism should be seen as an attempt to leverage nostalgia. In his text for The Moving Image, "Nostalgia Merchants: VHS Distribution in the Era of Digital Delivery," Daniel Herbert discusses the contemporary trend of genre film distributors releasing new and repertory titles on VHS. ${ }^{6}$ Both the Alamo Drafthouse and Joe Ziemba have engaged with and capitalized on this trend. Herbert frames the distribution format's resurgence as an "endeavor

\footnotetext{
${ }^{5}$ It is worth adding here that the Alamo Drafthouse is a full-service restaurant in addition to being a movie theater, and patrons will often order food and drink prior to the start of the film and have it delivered to their seat mid-presentation.

${ }^{6}$ Daniel Herbert, "Nostalgia Merchants: VHS Distribution in the Era of Digital Delivery," Journal of Film and Video; Englewood 69, no. 2 (Summer 2017): 3-19.
} 
to redefine VHS as a platform, making it a signifier of subcultural authenticity." Elsewhere in the same text, Herbert writes:

\begin{abstract}
In their search for increasingly obscure movies, the people at Cinefamily, Severin, and Mondo Video unearthed the shot-on-video horror movie as a new frontier at the bottom of American media culture. Releasing these movies on VHS functions as an act of honoring them, and in this way the distributors authenticate themselves. This aim for subcultural legitimacy also explains the VHS releases for movies that did not originate on video. ${ }^{7}$
\end{abstract}

To this point I would add that capitalizing on the format's subcultural capital also reaffirms its value, and this act of leveraging nostalgia should be interpreted as advocacy for a certain type of moving image preservation. In this instance, one recalls the "nitrate won't wait" campaign, and its fetishistic argument put forth by concerned parties to encourage nitrate film preservation over that of other materials. ${ }^{8}$ There is an insurmountable accumulation of works potentially significant to the history of genre cinema surviving on videotape, an obsolete and ephemeral carrier. One would hope that AGFA and the Alamo Drafthouse's efforts to foster renewed appreciation for VHS, be they altruistic or self-serving, will also foster greater awareness of what might potentially soon be lost.

The Alamo Drafthouse prides itself on being immune from traditional expectations of contemporary megaplexes, oscillating between a family-owned restaurant, an international cinema chain, and a cinematheque. For its part, AGFA breaks from traditional archival practices in their approach to moving image preservation, as access is prioritized above conservation and formatfaithful presentation. Furthermore, AGFA exclusively grants access to their preservations for financial profit.

\footnotetext{
${ }^{7}$ Daniel Herbert, "Nostalgia Merchants: VHS Distribution in the Era of Digital Delivery," Journal of Film and Video; Englewood 69, no. 2 (Summer 2017), 9.

${ }^{8}$ Anthony Slide, introduction to Nitrate Won't Wait: A History of Film Preservation in the United States (McFarland, 2000), 1.
} 
Nevertheless, I would argue that AGFA is ultimately suited to such an initiative because of the historic relationship between VHS and non-institutional film preservation. AGFA is largely operating along the same (informal) lines as Mike Vraney and other amateur archivists. Their decision to use the Video Vortex monthly series and home video releasing as platforms to make their content available monetizes their work in the absence of institutional grants like those offered by the NFPF, which does not support the preservation of materials "originally created for television or video." 9

There remains the question of whether their initiative is scalable. Many of the tapes in which they have expressed interest are not in Austin. However, the equipment necessary to enact VHS preservation is easily sourced and portable enough to be packaged and shipped to a desired repository like Scarecrow Video in Seattle. Indeed, AGFA's digitization model could mirror that of another Austin institution, the Texas Archive of the Moving Image (TAMI). TAMI does not archive physical media on-site, and instead retains digital copies they produce of media sourced externally. ${ }^{10}$ There also remains the question of whether AGFA will only target titles for preservation that they have deemed "orphaned" following due diligence, or if they will also preserve copyrighted material that is nevertheless deemed to be at-risk. Much of AGFA's preservation initiative remains germinal as of this paper's writing, and I believe that, as with many of the decisions the archive has made over the last decade, much of what shapes this initiative will not likely stem from a rigorously-planned approach. Instead, I believe the direction AGFA's

\footnotetext{
9 "National Film Preservation Foundation: Basic Preservation Grants," accessed June 4, 2019, https://www.filmpreservation.org/nfpf-grants/basic-preservation-grants. 10 "Texas Film Round-Up," Texas Archive of the Moving Image, accessed June 9, 2019, https://www.texasarchive.org/library/index.php?title=Texas_Film_Round-Up.
} 
project takes will largely be determined by the emerging needs of curators, the Alamo Drafthouse, and AGFA's ever-growing fandom. 


\section{Concluding Remarks}

From the outset, my motivating research question has concerned what it means for a cultural heritage institution like AGFA to preserve a historically non-institutional format like VHS tapes. I was also interested in what such an initiative might or should resemble. What I discovered during my residency is that to take on such a project, a cultural heritage institution must adjust their standards to cater to their preservation elements. Genre film VHS tapes may be low-fidelity approximations of their original source elements in some cases, but in many of those same cases they are the only known options remaining to save a particular title.

I also found that institutional VHS preservation of genre films largely resembles noninstitutional preservation initiatives, though with institutionalization comes clearly defined standards and access to resources. AGFA's approaches to curatorship, acquisition, and dissemination are comparable to those of non-institutional actors like Mike Vraney and other amateur/commercial media archivists. In fact, I believe that AGFA's project is only commercially viable because it resembles Vraney's "Something Weird" venture more than it does one upon which a FIAF affiliate might embark. This is not least because AGFA is appealing to the same fan culture that "Something Weird" did for financial support.

VHS has a demonstrated significance to the history of genre film distribution, production, and preservation. The format's value to genre film preservation has become clear following its commercial obsolescence, but non-institutional conservators like Mike Vraney were able to recognize its potential already at the time of its technological and cultural dominance. Vraney consistently referred to himself as first and foremost a conservator rather than a distributor, and I believe he was right to do so. 
The value of the "Something Weird" tape collection at AGFA is two-fold. It is an emblematic collection of paracinematic works, many of which owe their continued survival to "Something Weird." It is also a collection of artifacts that elucidate the practices and interests of one of the most prominent figures in the genre film home video market. That these tapes should form the foundation for the VHS preservation initiative of the American Genre Film Archive is quite fitting.

The digitization of this collection is vital, though the second phase of AGFA's project, in which they will rely on tapes from external sources, is sure to be even more consequential and work-intensive. Despite the challenges posed by their initiative, I believe AGFA is up to the task, and if their approach deviates from that of more traditional film archives at times, it will be in the interest of achieving their goal to save as many titles as possible.

With this research project, I sought to situate the American Genre Film archive within the academic discourse surrounding VHS and genre film, most of which was published before AGFA announced its project. I also sought to provide new insights into AGFA's function as a cultural heritage institution, the Alamo Drafthouse's role as a disseminator of genre cinema, and the cultural importance of the "Something Weird" tape collection.

Due to the time at which I joined the American Genre Film Archive as a researcher-inresidence, my work has been limited to AGFA's first tape acquisition and their intentions for their proposed project. AGFA is sure to move forward on their initiative, and it will be interesting to see what they manage to practically achieve. As of this writing no one knows how many tapes held at Scarecrow Video in Seattle will prove useful to AGFA's initiative. I am confident the number of titles will be substantial, and believe the Scarecrow Video VHS collection is worthy of its own research paper. Finally, discussion of audience reception should remain a key part of future 
research on this topic. It would be interesting, for example, to look further into the popularity of the Video Vortex screening series among Alamo Drafthouse patrons, and to question what audience members are experiencing when watching a VHS tape or transfer outside a living room setting. I personally found the experience profoundly strange and devoid of nostalgic attachment. Rather, it felt like something new entirely. 


\section{Bibliography}

“About - BLEEDING SKULL!” Accessed June 4, 2019. http://bleedingskull.com/about/.

"About This Collection | Selections from the National Film Registry | Digital Collections | Library of Congress." Digital Collection. Library of Congress, Washington, D.C. 20540 USA. Accessed June 4, 2019. https://www.loc.gov/collections/selections-from-the-national-film-registry/aboutthis-collection/.

Alilunas, Peter. Smutty Little Movies: The Creation and Regulation of Adult Video. Berkeley, UNITED STATES: University of California Press, 2016. http://ebookcentral.proquest.com/lib/ryerson/detail.action?docID=4453282.

- Smutty Little Movies: The Creation and Regulation of Adult Video, 2017. http://dx.doi.org/10.1525/california/9780520291706.001.0001.

Bartok, Dennis, and Jeff Joseph. A Thousand Cuts: The Bizarre Underground World of Collectors and Dealers Who Saved the Movies. 1 edition. Jackson: University Press of Mississippi, 2016.

Benson-Allot, Caetlin Anne. Killer Tapes and Shattered Screens: Video Spectatorship from VHS to File Sharing. Berkeley: University of California Press, 2014.

"Board | Scarecrow." Accessed April 7, 2019. http://blog.scarecrow.com/board/.

Carlson, Zack, and Bryan Connolly. Destroy All Movies!!!: The Complete Guide to Punks on Film. Seattle, Wash.: Fantagraphics Books, 2010.

Church, David. "Something Weird This Way Comes: Mike Vraney (1957-2014)." The Moving Image 14, no. 2 (2014): 51-67.

—. "The Untold Story of the Original, Factory-Produced, Horror/Exploitation VHS Collector." Flow 21, no. 2 (2014). https://www.flowjournal.org/2014/11/the-untold-story-of-the-vhscollecto/?print=print.

Desiderio, Matt, Josh Schafer, Dan Kinem, Levi Peretic, Horror Boobs \& Lunchmeat (Firm), and VHShitfest (Firm). Adjust your tracking, 2014.

Greenberg, Joshua M. From Betamax to Blockbuster (Inside Technology): Video Stores and the Invention of Movies on Video. Cambridge, Mass.; London: MIT Press, 2010.

Herbert, Daniel. "Nostalgia Merchants: VHS Distribution in the Era of Digital Delivery." Journal of Film and Video; Englewood 69, no. 2 (Summer 2017): 3-19.

- Videoland: Movie Culture at the American Video Store. First edition. Berkeley: University of California Press, 2014.

Hilderbrand, Lucas. "Inherent Vice: Access, Aesthetics, and Videotape Bootlegging." Ph.D., New York University, 2006. http://search.proquest.com/docview/305294367/abstract/6BB7E8E3D86A4A0EPQ/1. 
Horak, Jan-Christopher. “Archiving, Preserving, Screening 16mm.” Cinema Journal 45, no. 3 (July 31, 2006): 112-18. https://doi.org/10.1353/cj.2006.0033.

Jones, Steve. "Preserved for Posterity?: Present Bias and the Status of Grindhouse Films in the 'Home Cinema' Era." Journal of Film and Video 70, no. 1 (February 21, 2018): 3-16.

Kusnierz, Lauren Ashley. "Rebels, Nudie-Cuties, and Hipsters : A Study of the American Genre Film Archive," 2014. https://repositories.lib.utexas.edu/handle/2152/26549.

"National Film Preservation Foundation: Basic Preservation Grants." Accessed June 4, 2019. https://www.filmpreservation.org/nfpf-grants/basic-preservation-grants.

Pratt, Aaron T. "Horror and Exploitation on VHS: The History of Home Video Comes to Yale." Edited by Caetlin Benson-Allott and Eugenie Brinkema. Journal of Visual Culture 14, no. 3 (December 2015): 332-35. https://doi.org/10.1177/1470412915607925.

Rife, Katie. "The American Genre Film Archive Announces the next Stage in Its Mission: VHS!" News. Accessed April 7, 2019. https://news.avclub.com/the-american-genre-film-archiveannounces-the-next-stag-1829873801.

Schaefer, Eric. "Dirty Little Secrets: Scholars, Archivists, and Dirty Movies." The Moving Image 5, no. 2 (November 22, 2005): 79-105. https://doi.org/10.1353/mov.2005.0034.

Sconce, Jeffrey. "“Trashing' the Academy: Taste, Excess, and an Emerging Politics of Cinematic Style." Screen 36, no. 4 (December 1, 1995): 371-93. https://doi.org/10.1093/screen/36.4.371.

Slide, Anthony. Magnificent Obsession: The Outrageous History of Film Buffs, Collectors, Scholars, and Fanatics. 1 edition. Jackson: University Press of Mississippi, 2018.

Nitrate Won't Wait: A History of Film Preservation in the United States. Jefferson, N.C.; London: McFarland \& Co., 2001.

Something Weird Video. Fall 1993 Catalogue. Seattle, WA: Something Weird Video, 1993.

Sorrenti, Dax. VHS 2.0: Amateur Archiving on the Internet and the Nostalgic Reclamation of Retro Media. Vancouver: University of British Columbia, 2012. https://central.baclac.gc.ca/.item?id=TC-BVAU-41976\&op=pdf\&app=Library.

"Terror on Tape: An Interdisciplinary Symposium on the History of Horror on Video | Yale University Library.” Accessed June 4, 2019. https://web.library.yale.edu/news/2016/04/terrortape-interdisciplinary-symposium-history-horror-video.

“Texas Film Round-Up.” Texas Archive of the Moving Image. Accessed June 9, 2019. https://www.texasarchive.org/library/index.php?title=Texas_Film_Round-Up.

"Video Hate Squad - About." Accessed April 7, 2019. https://www.facebook.com/Video-Hate-Squad$\underline{121412867945137 / .}$. 
Vraney, Mike, interviewed in BigPoppaOnline. Third Eye Cinema podcast. May 6, 2012.

http://www.blogtalkradio.com/bigpoppaonline/2012/05/06/third-eye-cinema-5612-with-mikevraney. 